International Journal of

Advanced Science and Convergence

\title{
Smart Room Lighting System with Light Intensity Controller for Curtain and Light Appliances using Raspberry Pi
}

\author{
Renz Joseph E. Cruz ${ }^{1}$, Francis Von I. Ibardaloza ${ }^{1}$, Arsen Jayz M. Roga ${ }^{1}$, \\ King Lawrence M. Cuizon ${ }^{1}$, Nastaran Reza Nazar Zadeh ${ }^{1}$ and Rosalina R. Estacio ${ }^{1}$ \\ ${ }^{1}$ College of Computer Studies and Engineering, Jose Rizal University, Philippines
}

\begin{abstract}
Background/Objectives: Natural light is an essential strategy to reduce energy consumption. Methods/Statistical analysis: New living experiences acquire integration of technology in every aspect of life, and it seeks to help in saving energy which leads to a higher quality of life. Maximizing the use of natural light can reduce power consumption by up to $60 \%$ [1]. Findings: This study aims to propose a novel solution for smart rooms to conserve energy in the buildings by integrating the daylight with a curtain and light appliances MPU controller. The system integrates with a servo motor and LDR that control the window curtain to maximize the use of daylight. According to the change of sunshine intensity, this smart curtain controller system designed by adopting the photosensitive element and light-dependent resistor interfaced with Raspberry pi. Improvements/Applications: The proposed system can escalate the user in providing user-friendly operation and comfortable environment.
\end{abstract}

Index Terms

LDR, MPU, Photosensitive, Raspberry pi

\footnotetext{
Corresponding author: Nastaran Reza Nazar Zadeh

nastaran.nazar@mrsp-ph.org

- Manuscript received October 15, 2019.

- Revised November 19, 2019 ; Accepted December 20, 2019.

- Date of publication December 31, 2019.

(c) The Academic Society of Convergence Science Inc.

2619-8150 ( 2019 IJASC. Personal use is permitted, but republication/redistribution requires IJASC permission.
} 


\section{INTRODUCTION}

With the rapid development of control technology, home and office intelligent have become more and more popular. Automatic control technology and sensing technology in smart home and smart office has essential significance [2]. Curtains are widely used in the home and office environment. It has vital practical significance to study the automation and intelligence of curtain control. It can likewise provide a reference for the realization of the automation and smart control of other household appliances or office equipment.

Today, with the increasing development of automatic control technology, many appliances on our daily life have been changed [3], which can lead to improving quality of life. When automatic control technology has increased on demanding circumstances, the design of light control automatic curtain becomes more and more practical. Light sensitive automatic curtain controller based on the Light Dependent Resistor (LDR) to control the servo motor rotation is a great solution to conserve the use of energy by using the daylight.

The specific objectives of the study are:

1. Design and develop a smart room lighting system to conserve electrical energy.

2. Use Raspberry pi as an MPU for the system controller.

3. Integrate with photosensitive LDR sensor to detect the intensity level.

4. Automatically open and close the curtains, based on the light level.

5. Automatically turn on and off the light appliances to maintain light intensity level.

With the light control technology applied in the curtain control system, users do not need to remember the opening and closing of the curtain, most notably at the offices and schools. Compared with the traditional control method by a button, remote controller or manual operation, the proposed scheme has the advantages of simple operation, automation, high safety, and more. The study can benefit all homeowners, companies, offices, schools, and government by saving the energy and reducing the power consumption with automatically control the light intensity of the room through the smart system.

\section{RELATED WORKS}

The Raspberry Pi (Rpi) is developed in the United Kingdom. It is a single-board and a low cost MPU, which is very small and can be integrated in many projects. It is a little capable device that can be use by students and researchers to learn how to program in languages like Python and C. It can be used as a controller for different applications including IoT and Home Automation systems [4].

Using regular curtain blinds, it could control the intensity of light in the room and suit it according to the needs of the user. However, this task is cumbersome according to [5], compared with a curtain operation that can be automated using an Arduino and a stepper motor. In this project there are two ways for activating the curtains:

Integrate a sound sensor (mic) to control it using handclaps

. Using push buttons to move the shades of the curtain

The Arduino Curtain Automation system works when the controller receives input from either the sound sensor (mic) or buttons. It then correspondingly controls the stepper motor through the Darlington array driver for the motor. The stepper motor is attached to the control stick of the curtain blinds and thus on rotation, opens/closes the blinds. However, the project failed to implement an efficient use of the daylight to maintain the light intensity level.

\section{SySTEM DESCRIPTION}

The proposed system includes hardware and software components which is illustrated in Figure 1. The hardware components has three main parts: light detection module, light appliances and curtain controller. They are all integrated together with software using a Raspberry pi as an MPU.

\section{A. Hardware Components}

\section{A.1 Raspberry Pi 2}

This module is used as a heart of the system to integrate with all the hardware and software component. Raspberry Pi 2 has a 40-pin GPIO (general purpose input/output) which can be used to integrate with different sensors. Each of these GPIO pins can be program and design in software as an input or output [6].

In this proposed system the LDRs are connected through the GPIO pins and set as an input. Data read from the LDR (in voltage level) depending on light intensity detected is sent to Raspberry pin as digital signal to trigger the on/off operation of light appliances and roll up/down functions of the automated curtain. 


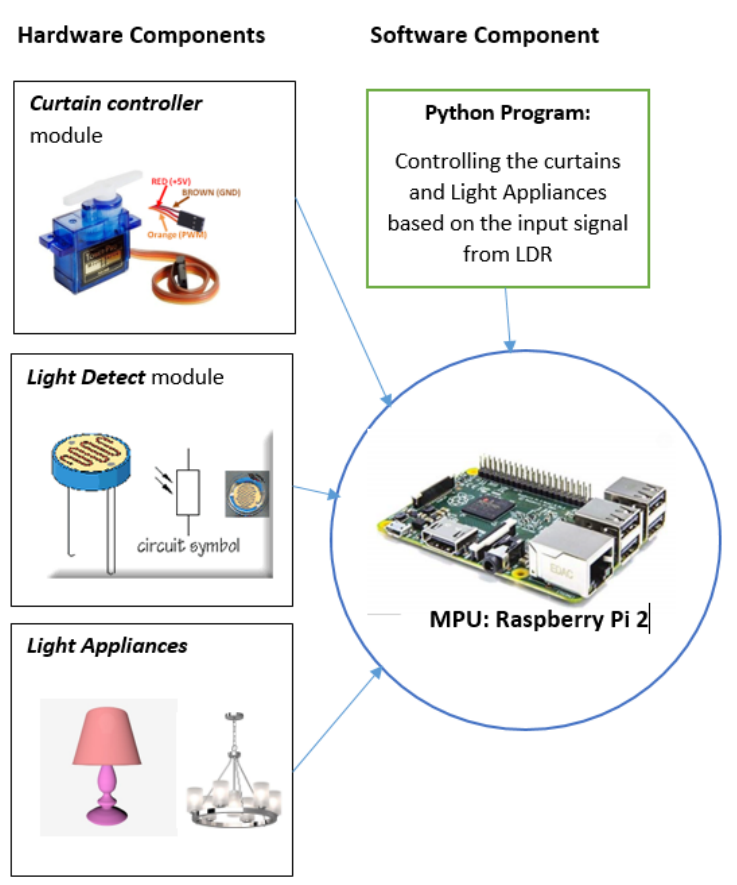

Fig. 1. Block Diagram of the system.

\section{A.2 Light Dependent Resistor (LDR)}

LDR is made up of semiconductor materials with high resistance. The working principle of LDR is based on the photo conductivity that is an optical phenomenon [7]. LDR's resistance is described when light falls on them. It increases when the room is dark and LDR's residency will be as high as $10^{12} \Omega$. It decreases when there is daylight or sunlight. So if a constant voltage is applied on the LDR and light intensity is increased then the current will start increasing as well, as depicted in Figure 2. It usually takes 8 to $12 \mathrm{~ms}$ for the photocell to change the resistance after light is incident while it will take about one or more seconds to risk back.

Light Dependent Resistor does not have any polarity, meaning negative and positive current can be connected to any of the leads (Figure 3). To interface the LDR with Rpi a capacitor is needed because the Raspberry Pi's GPIO pins are digital and to overcome this problem we should use it with a capacitor, so we still be able to measure resistance of the LDR [8]. When the capacitor charges, the voltage through the GPIO pin will rises and if the capacitor is charged to a certain point, the voltage rises above $2 \mathrm{~V}$, and the GPIO pin will be HIGH.

\section{A.3 Curtain Controller}

To maximize the use of daylight and conserve more energy, the curtain controller mechanism is implemented for automatic roll left/right of the curtain.

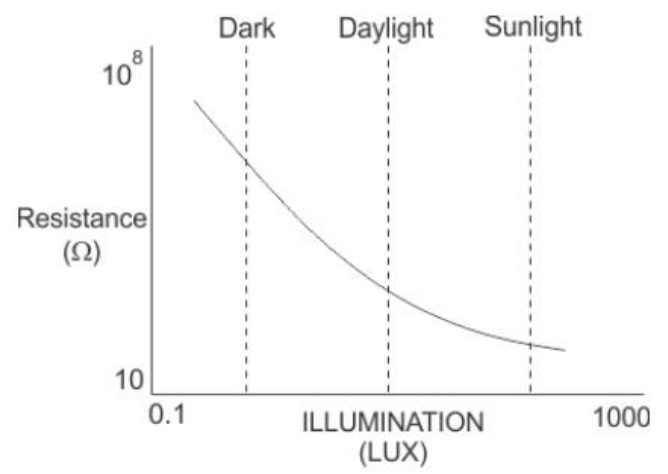

Fig. 2. Resistance vs. illumination curve for an LDR

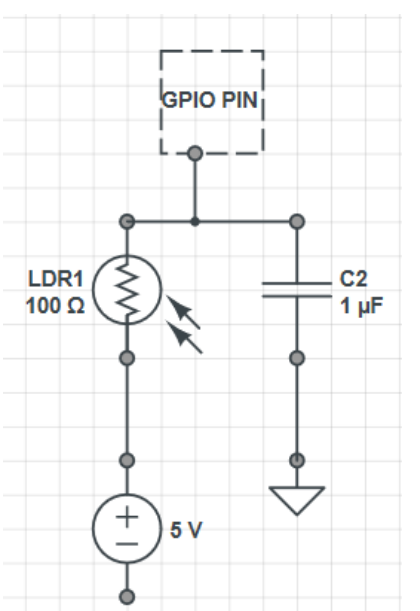

Fig. 3. Schematic of circuit for LDR

A servo motor is connected to the curtain; when the LDR is sensing the light, a control signal sends to the servo to open the curtain.

Controlling a servo motor is by sending a PWM (pulse width modulation) signals through the control wire. The working principle of a servo motor is based on receiving a pulse every $20 \mathrm{~ms}$, and we can determine how far the motor turns with the length of the pulse. See Figure 4 for the Python code of the servo controller.

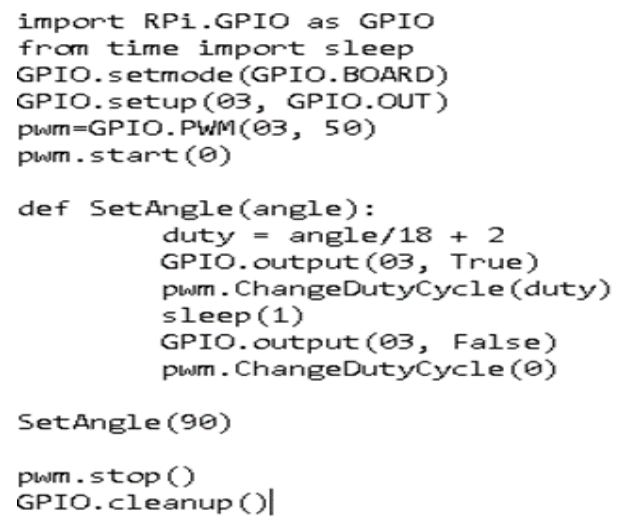


Fig. 4. Python codes for servo controller

\section{B. Light Appliances}

Light level or luminance refers to the total measure of brightness of light incident on a surface per unit area (lumens $/ \mathrm{m}^{2}$ or lux). Depending on light source used, different luminance values are available, sunlight as natural light source also emits different energy levels depending on natural conditions. A typical office room for example, requires 250 lumens $/ \mathrm{m}^{2}$ (EN 12464- Light and lighting of workplaces), therefore during full day where the sun emits 10,752 lux, a light appliance is not needed provided windows or curtains are open. However, during night time or cloudy day, natural light drops to 150 to 100 lux, so a light appliances can be used. To maintain desired light intensity level, this proposed study implements a controlled light appliances based on the light intensity level of two LDR. The relationship between the resistance and light intensity for a typical LDR can be expressed as:

$$
\mathrm{R}_{\mathrm{L}}=500 / \mathrm{Lux}, \quad \text { Equation (1) }
$$

Where:

$$
\begin{aligned}
& \mathrm{R}_{\mathrm{L}}=\mathrm{LDR} \text { resistance } \\
& \mathrm{Lux}=\text { lumens } / \mathrm{m}^{2}
\end{aligned}
$$

One LDR is used to measure the outside light intensity and the other one inside the room to maintain the specific amount of light in the room even during the cloudy days which the daylight might not be enough to reach enough light intensity level. MPU turns on enough number of light appliances by measuring the resistance level of indoor LDR to conserve energy.

\section{Software Component}

To control the hardware components, a Python program has been developed. There are two LDRs integrated to measure the light intensity level. One of them is to measure the resistance level of outside light, and the other is for measuring the resistance level of indoor light to maintain the light level in the room. Figure 5 shows the system flowchart for smart room lighting. In the proposed system the curtains being automatically open in the presence of daylight and the second LDR has been used to maintain the light in the room with turning on enough number of light appliances to save more electrical energy.

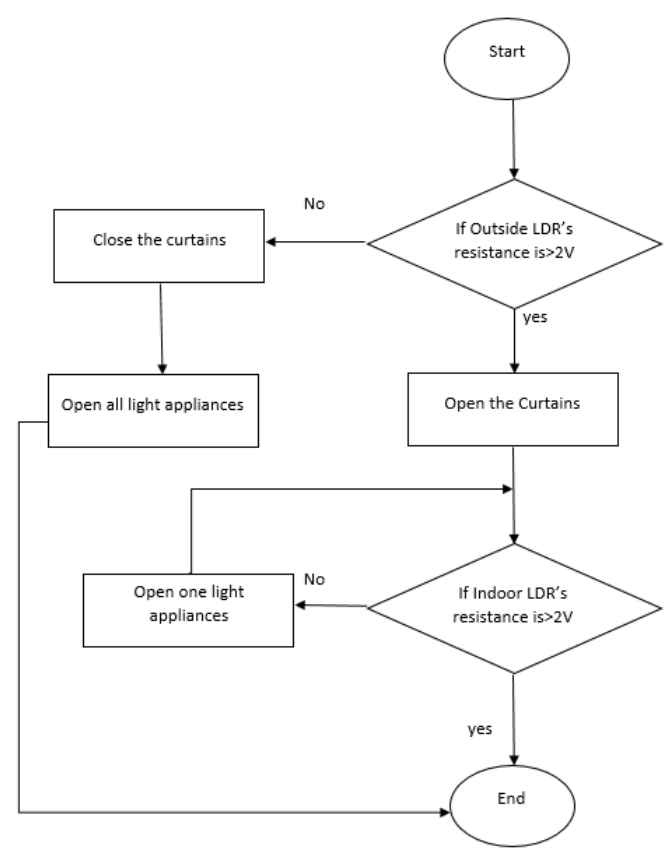

Fig. 5. System flowchart of smart room lighting

\section{EXPERIMENTATION \& RESULTS}

In this study a smart room lighting system with a light intensity controller for curtain and light appliances was designed and developed. For prototype purposes a room with LEDs (as light appliances) with a curtain has been developed, see Figure 6 (a) and (b).

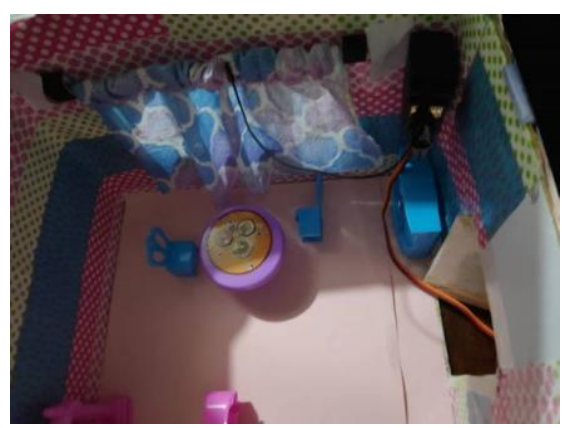

(a): Top view

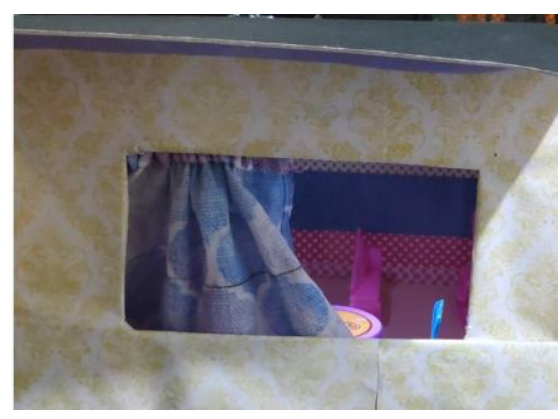

(b): side view

Fig. 6. Smart Room Lighting prototype 
To implement room light controller, different values of $5 \mathrm{~mm}$ super bright LEDs are used to simulate desired lighting and identify the number of light appliances to be used. In order to attain 250lux ideal for room use during dark night, 8 LEDs were simulated and LDR resistance is computed as shown in Table 1.

Table 1. Light Controller Test for LDR inside

\begin{tabular}{|c|c|c|c|}
\hline LED Type & $\begin{array}{c}\text { \# of } \\
\text { LEDS } \\
\text { used }\end{array}$ & $\begin{array}{c}\text { Lux } \\
\text { (lumens } / \mathbf{m}^{2}\end{array}$ & $\begin{array}{c}\text { Resistance } \\
\text { (Inside } \\
\text { LDR) }\end{array}$ \\
\hline $\begin{array}{c}5 \mathrm{~mm}, 2.6 \mathrm{lux}, \\
60^{0} \\
\end{array}$ & 8 & 187 & $2.5 \mathrm{k} \Omega$ \\
\hline $\begin{array}{c}5 \mathrm{~mm}, 2 \operatorname{lux}, \\
28^{\circ} \\
\end{array}$ & 8 & 123 & $4 \mathrm{k} \Omega$ \\
\hline $\begin{array}{c}5 \mathrm{~mm}, \\
13.5 \mathrm{lux}, 43^{\circ}\end{array}$ & 8 & 214.2 & $1 \mathrm{k} \Omega$ \\
\hline
\end{tabular}

Based on Table 1, it shows that the ideal type of LED is $5 \mathrm{~mm}$ super bright LED with $20 \mathrm{~mA}, 3.1 \mathrm{v}$, and using 8pcs of this type can attain 214 lux which is closely ideal to desired light intensity level with LDR resistance of $1 \mathrm{k} \Omega$.

To simulate the curtain controller function, the voltage divider rule is applied and MPU computes the resulting voltage and LDR values. The 5 volt supply is split between the LDR and the $5 \mathrm{k} \Omega$ resistor. The LDR connects to $5 \mathrm{~V}$, the resistor connects to ground, and the point in between connects to analog input 0.As the LDR's resistance changes, the fraction of the voltage across the two resistors changes as well. The Raspberry pi and the LCD displays the resistance that the LDR is exhibiting.

Table 2. Curtain Controller Test for LDR outside with varying distance

\begin{tabular}{|c|c|c|}
\hline Trial & Action & $\begin{array}{c}\text { LDR } \\
\text { resistance }\end{array}$ \\
\hline 1 & $\begin{array}{c}100 \% \text { Not } \\
\text { covered }\end{array}$ & 4.9 \\
\hline 2 & $75 \%$ covered & 17.8 \\
\hline 3 & $50 \%$ covered & 71.2 \\
\hline 4 & $25 \%$ covered & 804.3 \\
\hline 5 & 100 covered & $2.5 \mathrm{k}$ \\
\hline
\end{tabular}

\section{Conclusion}

Smart lighting system can be used for home automation, offices, schools, restaurants, and any public places with window and curtain to conserve electrical energy. In this project light dependent resistors have been used to measure the intensity level inside the room. A servo motor is used to control the curtains to maximize the use of daylight. For saving more electrical energy, especially during the sunset or cloudy days, this smart system turns on enough number of light appliances using Raspberry pi 2 to maintain the light level inside the room.

Further works can focus on the actual implementation of smart room lighting system by using different lighting fixtures at different room dimensions and settings.

\section{REFERENCES}

[1] E. J. Gagoa, T. Muneerb, M. Knezc \& H. Kösterd. (2015). Natural light controls and guides in buildings. Energy saving for electrical lighting, reduction of cooling load. Renewable and Sustainable Energy Reviews, Volume 41, 1-13

[2] Y. Xu, C.Z. Wu, C.G. Wu. (2016). The design of intelligent Home Furnishing integrated voice control system based on LD3320. Journal of shangqiu teachers college, 32(6), 37-41.

[3] Zhiwei Jiao, Weimin Yang, Pengcheng Xie \& Xingtian Wang. (2010). Automatic control and energy-saving mechanism of internal circulation two-platen injection molding machine, 2010 International Conference on Mechanic Automation and Control Engineering.

[4] Himanshu Singh, Vishal Pallagani, Vedant Khandelwal \& U. Venkanna. (March, 2018). IoT based smart home automation system using sensor node. 2018 4th International Conference on Recent Advances in Information Technology (RAIT).

[5] A. Tsangrassoulisa, A. Kontadakisa \& L. Doulosb. (2017). Assessing Lighting Energy Saving Potential from Daylight Harvesting in Office Buildings Based on Code Compliance \& Simulation Techniques: A Comparison. Procedia Environmental Sciences, 38, 420-427.

[6] Sarthak Jain \& Anant Vaibhav. Lovely Goyal. (February, 2014). Raspberry Pi based interactive home automation system through E-mail. 2014 International Conference on Reliability Optimization and Information Technology (ICROIT).

[7] Nurfarhana Nasrudin, Nur M. Ilis \& Tan P. Juin. (March, 2011). Analysis of the light dependent resistor configuration for line tracking robot application. 2011 IEEE 7th International Colloquium on Signal Processing and its Applications.

[8] J. Nikhila. (September, 2017). Web based Environmental Monitoring System using Raspberry P $i$, 2017 International Conference on Current Trends in Computer, Electrical, Electronics and Communication (CTCEEC).

[9] Iful Amri, Elisabeth Dian Atmajati \& Rahmat Awaludin Salam. (August, 2016). Potentiometer a simple light dependent resistor-based digital. 2016 International Seminar on Sensors, Instrumentation, Measurement and Metrology (ISSIMM).

[10] Braham Lawas Lawu \& Maulana Yusuf Fathany. (May, 2016). Prototyping design of mechanical based end-devices for smart home applications. 2016 4th International Conference on Information and Communication Technology (ICoICT). 
[11] S. Palaniappan, N. Hariharan, N. T Kesh, V. S. \& A. Deborah S. (2015). Home automation systems - A study. International Journal of Computer Applications, 116(II), 11-18.

[12] N. M. Morshed, G. M. Muid-Ur-Rahman, M. R. Karim \& H. U. Zaman. (2015). Microcontroller based home automation system using Bluetooth, GSM, Wi$\mathrm{Fi}$ and DTMF. 2015 International Conference on Advances in Electrical Engineering (iCAEE), Dhaka, 2015, pp.101-104.

[13] N. Skeledzija, J. C. Edin, V. Bachler, H. N. Vucemilo \& H. Dzapo. (2014). Smart home automation system for energy efficient housing. 37th International Convention on Information and Communication Technology, Electronics and Microelectronics (MIPRO), 2014, pp.166-171.

[14] Siddarthan Chitra Suseendran \& Nanda Kishore B. (October, 2018). Smart Street lighting System. 2018 3rd International Conference on Communication and Electronics Systems (ICCES).

[15] Sunayana S. Badgelwar \& Himangi M. Pande. (February, 2017). Survey on energy efficient smart street light system. 2017 International Conference on I-SMAC (IoT in Social, Mobile, Analytics and Cloud) (I-SMAC). 